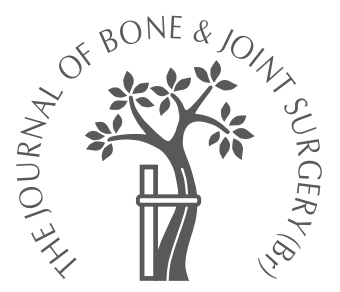

C. Gerber,

C. M. L. Werner, P. Vienne

From the University of Zürich, Balgrist, Switzerland
C. Gerber, MD, Professor and Chairman

C. M. L. Werner, MD, Resident

P. Vienne, MD, Staff

Member

Department of Orthopaedics, University of Zürich, Balgrist, Forchstrasse 340, 8008 Zürich, Switzerland.

Correspondence should be sent to Professor C. Gerber.

(C)2004 British Editorial Society of Bone and Joint Surgery doi:10.1302/0301-620X.86B6. $14577 \$ 2.00$

$J$ Bone Joint Surg [Br] 2004;86-B:848-55.

Received 30 April 2003;

Accepted after revision

4 November 2003

\title{
Internal fixation of complex fractures of the proximal humerus
}

We treated 34 consecutive articular fractures of the proximal humerus in 33 patients with good bone quality by open reduction and internal fixation. Anatomical or nearly anatomical reduction was achieved in 30, at a mean follow-up of 63 months (25 to 131), complete or partial avascular necrosis had occurred in 12 cases $(35 \%)$. Two patients subsequently underwent arthroplasty and six further patients required additional surgery. The 32 patients who did not require arthroplasty obtained a mean Constant score of 78 points or $89 \%$ of an age- and gender-matched normal score $(66$ points or $76 \%$ in the presence and 83 points or $96 \%$ in the absence of avascular necrosis $(p<0.0005)) ; 22$ were painfree, and seven had mild pain and three moderate pain. The mean active anterior elevation was $156^{\circ}$. Internal fixation of complex fractures of the proximal humerus restored good shoulder function if avascular necrosis did not develop.

Approximately $80 \%$ of the fractures of the proximal humerus are neither displaced nor markedly unstable and conservative treatment usually gives good or excellent results. ${ }^{1,2}$ In the remaining $20 \%$, the fracture fragments are displaced, unstable and may have disruption of their blood supply. Treatment of these fractures remains controversial..$^{3-6}$

Displaced and unstable extra-articular fractures are most commonly treated by operative reduction and fixation using various techniques. ${ }^{6,7}$ Treatment is more controversial for articular fractures which carry a high risk of avascular necrosis and subsequent collapse of the humeral head. In Neer's classification, ${ }^{1,2}$ these are the two-part anatomical neck, the three-part and four-part fractures and those with dislocation of the head of the humerus.

A review of the published results suggests that there is no universally accepted form of treatment. Conservative management may be associated with nonunion, malunion and avascular necrosis resulting in painful dysfunction. ${ }^{1,5,8,9}$ Primary hemiarthroplasty is favoured by many authors ${ }^{1,5,10-12}$ but is associated with a large number of complications and objective functional results which are disappointing. ${ }^{3,13}$ Open reduction and internal fixation with plates and screws may restore the anatomy of the proximal humerus but may also further compromise the vascularity of the head, leading to avascular necrosis and poor outcome. ${ }^{4,5,9,14}$ Studies which report poor results of internal fixation have often been carried out on elderly patients with poor bone quality and have not assessed the quality of the reduction obtained with operative intervention. ${ }^{4,5}$ Conversely, series with a favourable outcome have frequently consisted of younger patients with good bone quality, who had sustained impacted fractures ${ }^{6,15,16}$ for which anatomical reduction was obtained using a relatively non-invasive approach with minimal internal fixation. Interestingly, favourable results have been reported despite subsequent avascular necrosis. ${ }^{17}$

We have reviewed the clinical and radiological outcome of open reduction and internal fixation in a consecutive series of complex fractures of the proximal humerus with good bone quality.

\section{Patients and Methods}

We treated 35 consecutive patients with 36 complex fractures of the proximal humerus by open or closed reduction and minimal internal fixation. The bone quality was judged to be good with strong trabeculae in the cephalic segment and a thickness of the cortex of the proximal diaphysis of more than $3.5 \mathrm{~mm} .{ }^{18}$

One patient with multiple sclerosis could not be re-examined because of her poor medical condition; and a second patient had left the country and could not be contacted. This left a total of 34 fractures sustained by 19 men and 14 women (one bilateral) with a mean age of 
Table I. Details of the patients, the type of fracture and the treatment

\begin{tabular}{|c|c|c|c|c|c|}
\hline Case & Gender & $\begin{array}{l}\text { Age } \\
\text { (yrs) }\end{array}$ & Type of fracture & Side & Type of treatment \\
\hline 1 & $\mathrm{~F}$ & 73 & 3-part, valgus-impacted & Left & Closed reduction, percutaneous pinning \\
\hline 2 & M & 37 & 3-part, dislocated & Left & Open reduction, autogenous bone graft, pinning \\
\hline 3 & M & 49 & 4-part, dislocated & Left & Open reduction, pinning \\
\hline 4 & M & 49 & 3-part, valgus-impacted & Right & Open reduction, autogenous bone graft, osteosuture \\
\hline 5 & M & 22 & 2-part, anatomical neck & Left & Open reduction, screw fixation \\
\hline 6 & M & 16 & 2-part, anatomical neck & Left & Open reduction, screw fixation \\
\hline 7 & M & 37 & 4-part, valgus-impacted & Right & Open reduction, plate fixation, osteosuture \\
\hline 8 & $\mathrm{~F}$ & 27 & 4-part, dislocated & Right & Open reduction, pinning \\
\hline 9 & $\mathrm{~F}$ & 21 & 3-part, dislocated & Left & Closed reduction, percutaneous pinning \\
\hline 10 & $\mathrm{~F}$ & 46 & 3-part, valgus-impacted & Left & Open reduction, pinning \\
\hline $11^{*}$ & $\mathrm{~F}$ & 54 & 3-part, valgus-impacted & Right & Open reduction, autogenous bone graft, osteosuture \\
\hline $12^{*}$ & $\mathrm{~F}$ & 54 & 4-part, valgus-impacted & Left & Open reduction, autogenous bone graft, osteosuture \\
\hline 13 & $\mathrm{~F}$ & 26 & 4-part, valgus-impacted & Left & Open reduction, pinning \\
\hline 14 & $\mathrm{~F}$ & 56 & 4-part, valgus-impacted & Right & Open reduction, autogenous bone graft, osteosuture \\
\hline 15 & M & 33 & 4-part, dislocated & Right & Open reduction, screw fixation \\
\hline 16 & M & 39 & 3-part (4th part isolated) & Right & Open reduction, allogenous bone graft, osteosuture \\
\hline 17 & M & 37 & 3-part (4th part isolated) & Left & Closed reduction, percutaneous pinning \\
\hline 18 & M & 33 & 3-part valgus-impacted & Right & $\begin{array}{l}\text { Open reduction, autogenous bone graft, osteosuture } \\
\text { screw fixation }\end{array}$ \\
\hline 19 & $\mathrm{~F}$ & 49 & 4-part, valgus-impacted & Right & Open reduction, autogenous bone graft, osteosuture \\
\hline 20 & M & 50 & 4-part, valgus-impacted & Right & $\begin{array}{l}\text { Open reduction, autogenous bone graft, osteosuture } \\
\text { screw fixation }\end{array}$ \\
\hline 21 & $\mathrm{~F}$ & 64 & 4-part, valgus-impacted & Right & Open reduction, autogenous bone graft, osteosuture \\
\hline 22 & $\mathrm{~F}$ & 65 & 4 -part & Right & Open reduction, plate fixation, osteosuture \\
\hline 23 & M & 52 & 3-part (4th part isolated) & Left & Open reduction, plate fixation, osteosuture \\
\hline 24 & M & 38 & 3-part, (2-part plus head-split) & Left & Open reduction, osteosuture \\
\hline 25 & M & 42 & 3-part (4th part isolated) & Right & Open reduction, autogenous bone graft, osteosuture \\
\hline 26 & $\mathrm{~F}$ & 60 & 4-part & Left & Open reduction, allogenous bone graft, osteosuture \\
\hline 27 & M & 32 & 3-part dislocated & Right & Open reduction, plate fixation, osteosuture \\
\hline 28 & M & 56 & 4-part dislocated & Right & Open reduction, screw fixation, osteosuture \\
\hline 29 & M & 55 & 4-part valgus-impacted & Left & Open reduction, pinning \\
\hline 30 & $\mathrm{~F}$ & 32 & 3-part (4th part isolated) & Right & Open reduction, plate fixation \\
\hline 31 & M & 47 & 4-part, head-split & Right & Open reduction, plate fixation \\
\hline 32 & M & 70 & 3-part valgus-impacted & Right & Open reduction, plate fixation \\
\hline 33 & $\mathrm{~F}$ & 50 & 3-part valgus-impacted & Left & Open reduction, autogenous bone graft, osteosuture \\
\hline 34 & $\mathrm{~F}$ & 55 & 4-part, dislocated & Left & Open reduction, plate fixation, osteosuture \\
\hline
\end{tabular}

44.9 years (16 to 73 ) and a mean delay between injury and operation of 3.2 days ( 0 to 14 ). Table I gives the clinical details of the patients.

The basis of classification was according to Neer's criteria. ${ }^{1}$ To address the problems of reproducibility, ${ }^{19,20}$ the fractures were classified by a consensus of all three authors using a true anteroposterior (AP), an axillary lateral and a scapular lateral view with, if necessary, additional consultation of the operation notes. There were two displaced twopart anatomical neck fractures and 16 three-part fractures. Seven of the latter were valgus-impacted, three were threepart fracture-dislocations, one a three-part fracture with a head-split component, and five three-part fractures with an isolated head fragment (fourth part fractured but not displaced). The remaining 16 four-part fractures consisted of ten classic four-part fractures, five four-part fracture-dislocations, and one four-part fracture with an additional headsplit component.

Three valgus-impacted fractures undisplaced at the calcar were treated by closed reduction and percutaneous pinning under fluoroscopic control. A rasp was introduced percutaneously between the greater and the lesser tuberos- ities to elevate the lateral aspect of the head segment. After elevation of the head, the greater tuberosity reduced spontaneously or with a minimal pressure using the rasp through the same incision. The fracture was then stabilised by two pins into the head and with one or two terminally threaded pins passed through the greater tuberosity into the medial diaphyseal cortex.

We reduced 31 fractures through a deltopectoral approach. The tuberosities were touched as little as possible. A rasp was introduced through the anterior vertical line of the fracture line between the greater tuberosity and shaft. The fragment of the greater tuberosity was inspected from inside and positioned so that its distal triangular tip was reduced in the corresponding defect in the shaft. The rasp was then brought underneath the lateral aspect of the humeral head which was elevated until the cartilage was flush with the insertion of the cuff at the greater tuberosity. This was then approximated towards the shaft and could usually be relocated without difficulty. The humerus was rotated and the fracture was stabilised. If the lateral or anterior cortex was multifragmentary, plate fixation was used. If splinting one of the fragments seemed to be appropriate pins 
Table II. The outcome of treatment

\begin{tabular}{|c|c|c|c|c|c|c|c|c|c|c|c|}
\hline Case & Malunion & $\begin{array}{l}\text { Avascular } \\
\text { necrosis }\end{array}$ & $\begin{array}{l}\text { Constant } \\
\text { score }\end{array}$ & $\begin{array}{l}\text { SSV } \\
(\%)\end{array}$ & $\begin{array}{l}\text { Secondary } \\
\text { arthroplasty }\end{array}$ & Flexion ( ${ }^{\circ}$ ) & $\begin{array}{l}\text { Abduction } \\
\text { (') }\end{array}$ & $\begin{array}{l}\text { External } \\
\text { rotation }\left({ }^{\circ}\right)\end{array}$ & $\begin{array}{l}\text { Internal } \\
\left.\text { rotation ( }{ }^{\circ}\right)\end{array}$ & Pain & Re-operation \\
\hline 1 & No & None & 95 & 100 & No & 160 & 170 & 45 & 85 & No & \\
\hline 2 & No & None & 92 & 95 & No & 160 & 160 & 30 & 110 & No & \\
\hline 3 & No & Partial & 95 & 85 & No & 170 & 170 & 30 & 90 & No & \\
\hline 4 & No & Total & 71 & 80 & No & 100 & 90 & 5 & 90 & Mild & \\
\hline 5 & No & Partial & 95 & 100 & No & 170 & 170 & 60 & 110 & No & \\
\hline 6 & No & None & 100 & 95 & No & 170 & 170 & 70 & 100 & No & \\
\hline 7 & No & None & 92 & 80 & No & 160 & 155 & 70 & 80 & No & \\
\hline 8 & No & Total & 70 & 45 & No & 160 & 160 & 20 & 90 & Moderate & \\
\hline 9 & No & Partial & 46 & 70 & No & 120 & 100 & 45 & 100 & Mild & \\
\hline 10 & No & Total & 81 & 70 & No & 160 & 150 & 20 & 90 & Mild & \\
\hline $11 *$ & No & None & 100 & 85 & No & 170 & 170 & 20 & 100 & No & \\
\hline $12^{*}$ & No & None & 100 & 85 & No & 170 & 160 & 20 & 100 & No & \\
\hline 13 & No & None & 100 & 90 & No & 170 & 170 & 30 & 110 & Mild & \\
\hline 14 & No & None & 100 & 95 & No & 170 & 170 & 50 & 100 & No & \\
\hline 15 & No & None & 100 & 95 & No & 170 & 170 & 50 & 90 & No & \\
\hline 16 & No & Total & & & Yes & & & & & Moderate & Total shoulder replacement \\
\hline 17 & No & None & 82 & 85 & No & 170 & 120 & 45 & 110 & No & \\
\hline 18 & No & None & 95 & 100 & No & 170 & 170 & 60 & 110 & No & \\
\hline 19 & No & None & 100 & 100 & No & 170 & 170 & 20 & 100 & No & \\
\hline 20 & No & Partial & & & Yes & & & & & Moderate & $\begin{array}{l}\text { Arthroscopic capsulotomy, } \\
\text { biceps tenotomy, subacromial } \\
\text { decompression, total shoulde } \\
\text { replacement }\end{array}$ \\
\hline 21 & No & Partial & 100 & 75 & No & 155 & 150 & 40 & 110 & No & \\
\hline 22 & No & None & 100 & 100 & No & 115 & 135 & 50 & 85 & No & \\
\hline 23 & Yes & None & 100 & 100 & No & 165 & 170 & 40 & 95 & No & \\
\hline 24 & No & None & 96 & 95 & No & 150 & 165 & 45 & 110 & No & \\
\hline 25 & No & None & 72 & 90 & No & 160 & 160 & 45 & 80 & Mild & Arthroscopic capsulotomy \\
\hline 26 & No & Total & 61 & 50 & No & 85 & 90 & 5 & 40 & Mild & \\
\hline 27 & No & None & 98 & 95 & No & 165 & 160 & 70 & 110 & No & $\begin{array}{l}\text { Implant removal } \\
\text { Adhesiolysis }\end{array}$ \\
\hline 28 & No & None & 100 & 120 & No & 160 & 170 & 65 & 95 & No & \\
\hline 29 & No & None & 100 & 100 & No & 160 & 160 & 25 & 70 & No & \\
\hline 30 & No & None & 83 & 80 & No & 150 & 130 & 20 & 85 & Mild & Implant removal \\
\hline 31 & Yes & Partial & 61 & 80 & No & 100 & 90 & 35 & 45 & No & Implant removal \\
\hline 32 & Yes & None & 100 & 100 & No & 165 & 170 & 40 & 95 & No & $\begin{array}{l}\text { Implant removal } \\
\text { Adhesiolysis, evacuation of } \\
\text { haematoma }\end{array}$ \\
\hline 33 & No & None & 95 & 85 & No & 165 & 160 & 40 & 90 & No & \\
\hline 34 & Yes & Partial & & 75 & No & & & & & No & $\begin{array}{l}\text { Implant removal } \\
\text { Bursectomy }\end{array}$ \\
\hline
\end{tabular}

* same patient

or screws were used. If maintaining the position of a major cortical fragment seemed to be necessary we used osteosutures. The methods of fixation for each patient are shown in Table I. Radiographs were obtained at the end of the procedure, with the wounds still open. If corrections were considered to be necessary they were carried out immediately.

Post-operative management was dependent on the stability which had been achieved operatively. Generally, pendulum exercises were started immediately and performed twice daily. A sling was worn for three weeks.

One of the 33 patients could only be interviewed over the telephone and sent new radiographs for inclusion in the study as she had moved abroad. The other 32 were examined at a mean of 63 months (25 to 131) after surgery and scored by two observers (CMLW and PV) who did not include the operating surgeon. Examination included a structured interview, physical examination and photographic documentation of shoulder function as well as scoring according to Constant and Murley ${ }^{21}$ using the technique described by Gerber, Fuchs and Hodler. ${ }^{22}$ In addition, the patients were asked to estimate the function of their shoulder in percentage terms as compared with a normal shoulder. This value was called the subjective shoulder value $(\mathrm{SSV}) .^{22}$

Radiological assessment included AP views in neutral and internal rotation, an axillary lateral and a Neer scapular lateral view. The quality of reduction, healing, formation of ectopic bone, development of glenohumeral osteoarthritis or avascular necrosis of the head were assessed.

Statistical analysis. This was performed by a statistical consultant using the Mann-Whitney U test, Fisher's exact test and the Kruskal-Wallis rank and Spearman rank-correlation tests. The level of significance was set to $p \leq 0.05$.

\section{Results}

All the fractures healed without delayed or nonunion of any segments. 


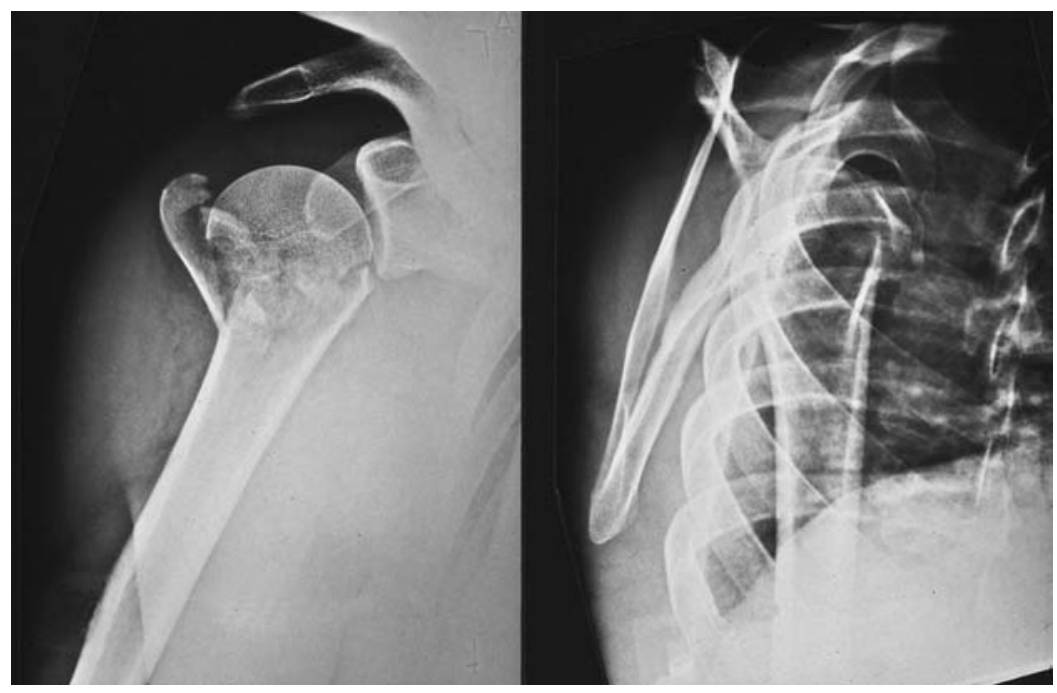

Fig. 1

Radiographs of a three-part fracture with a fractured but undisplaced fourth part.

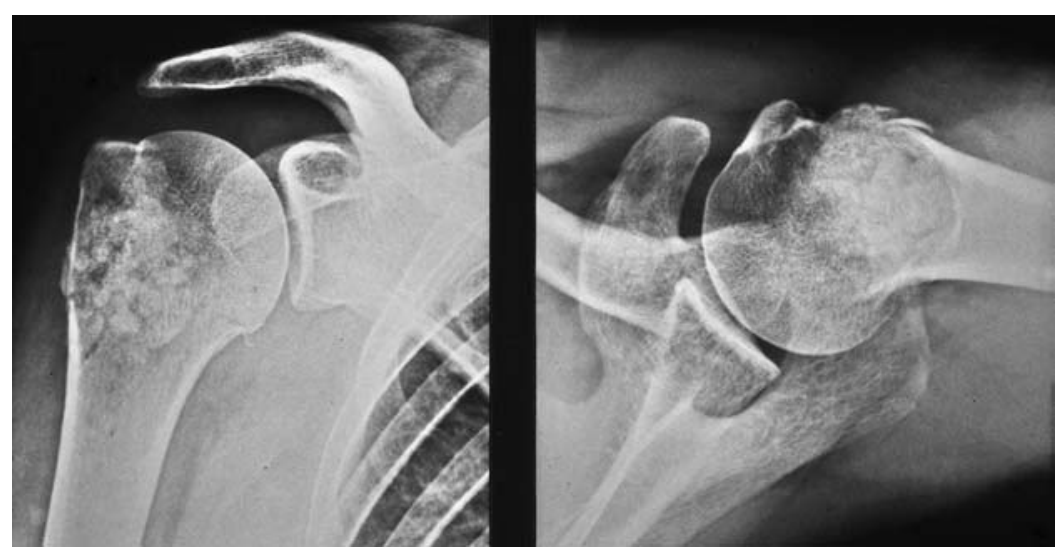

Fig. 2

Radiographs showing open reduction and internal fixation using bone graft and suture fixation.

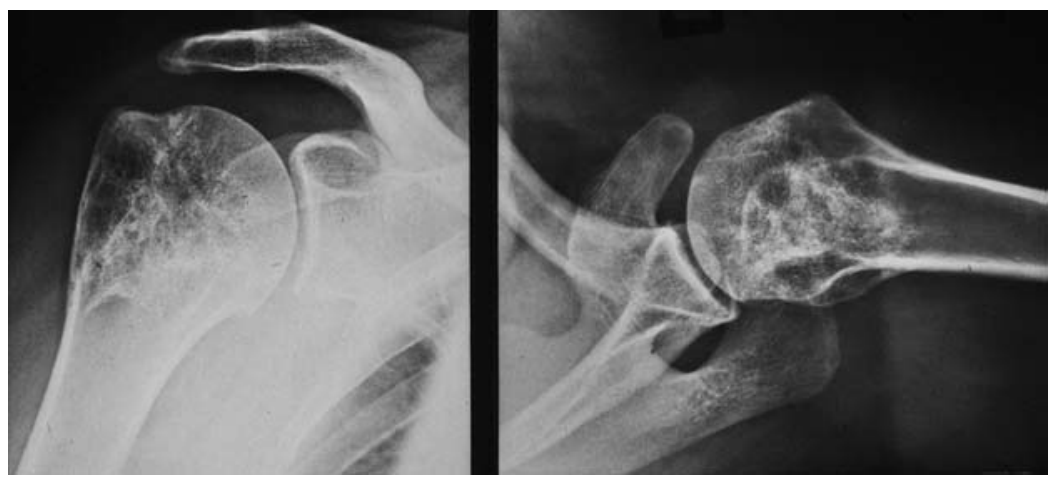

Fig. 3

Radiographs one year after operation with no evidence of avascular necrosis.

The operative goal to reduce the fracture anatomically or near anatomically was met in 30 of the 34 fractures. Displacement of at least $1 \mathrm{~cm}$ or of $45^{\circ}$ of one fragment was present in four fractures which were considered to be malunited (Table II).

In all of these cases a plate was used (twice with additional screws, twice with additional osteosutures), without a bone graft and the malunion occurred at surgery. There were no cases of malunion in the 13 fractures with bone graft compared with four in the 21 without graft. Bone grafting did not significantly reduce the rate of malunion.

Twelve of the 34 cases $(35 \%)$ showed evidence of avascular necrosis of the cephalic fragment. This involved only parts of the head in seven $(20.6 \%)$ and was total in five $(14.7 \%)$. Bone grafting was not significantly associated with the development of avascular necrosis. Both fractures 


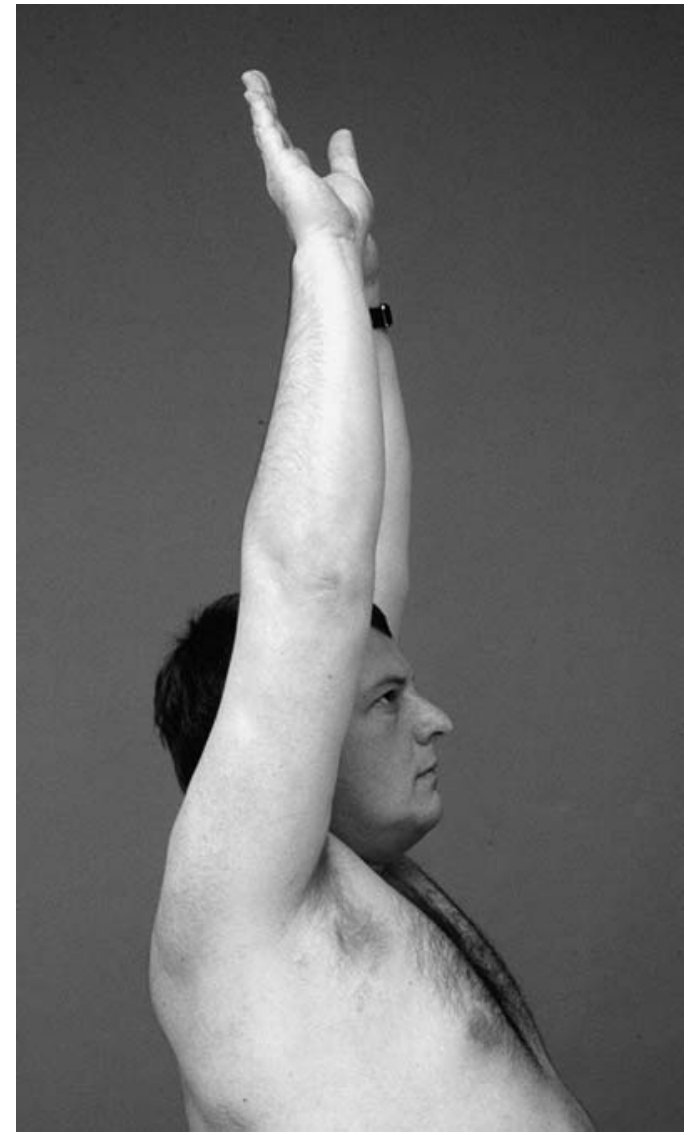

Fig. 4

Photograph showing that the patient has a pain-free, fully functional shoulder one year after operation.

in which allograft was used, however, had complete avascular necrosis.

Two patients $(6 \%)$ with total and painful avascular necrosis and a subjectively unsatisfactory result underwent total shoulder replacement 57 and 27 months respectively after the initial operation. One patient was followed at our institution and has a good result with a Constant score of $75 \%$ and a SSV of $80 \% 24$ months after total shoulder replacement. The second patient elected to have further treatment elsewhere and did not wish to be reviewed or to respond to a questionnaire because he was dissatisfied with the outcome of treatment and was therefore lost to followup when total shoulder replacement became necessary.

Six patients underwent seven additional operations, five implant removals, four of which were associated with release of subacromial adhesions, one evacuation of a haematoma and one arthroscopic capsulotomy for stiffness.

The functional results for the 32 shoulders which did not require total shoulder replacement were assessed at a mean of 63 months (25 to 131) after the initial operation with clinical assessment in 31 and telephone interview in one. The mean final Constant score was 77 points or $88.7 \%$ of a normal shoulder (46 to 100). The mean subjective shoul-
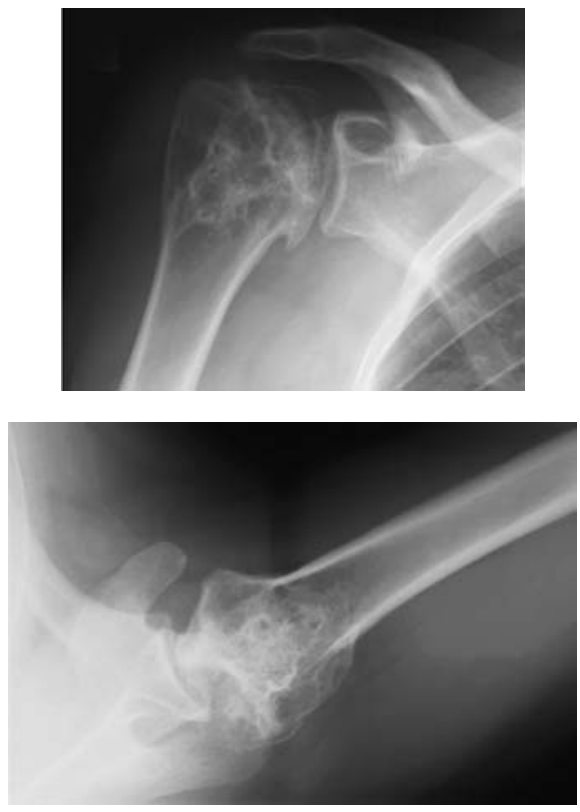

Fig. 5

Radiographs showing a collapsed humeral head due to avascular necrosis at three years.

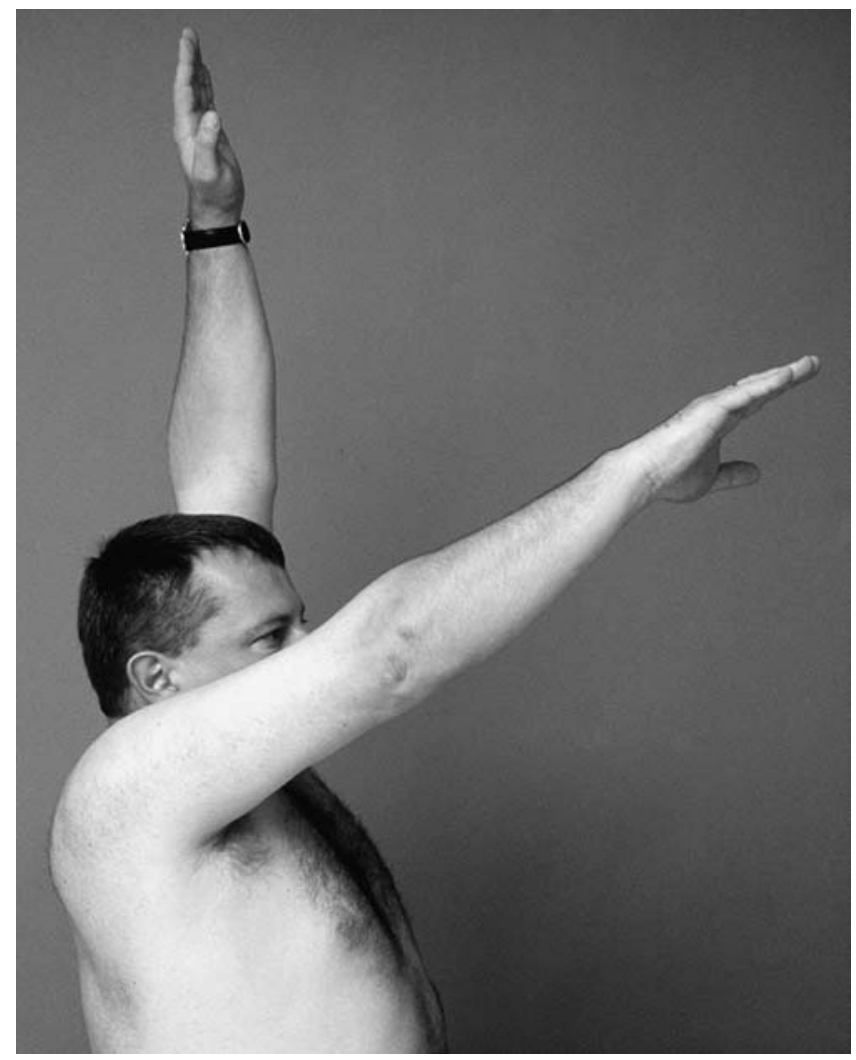

Fig. 6

Photograph showing that after a long period with subjectively normal shoulder, the patient had increasing pain and decreased function. 

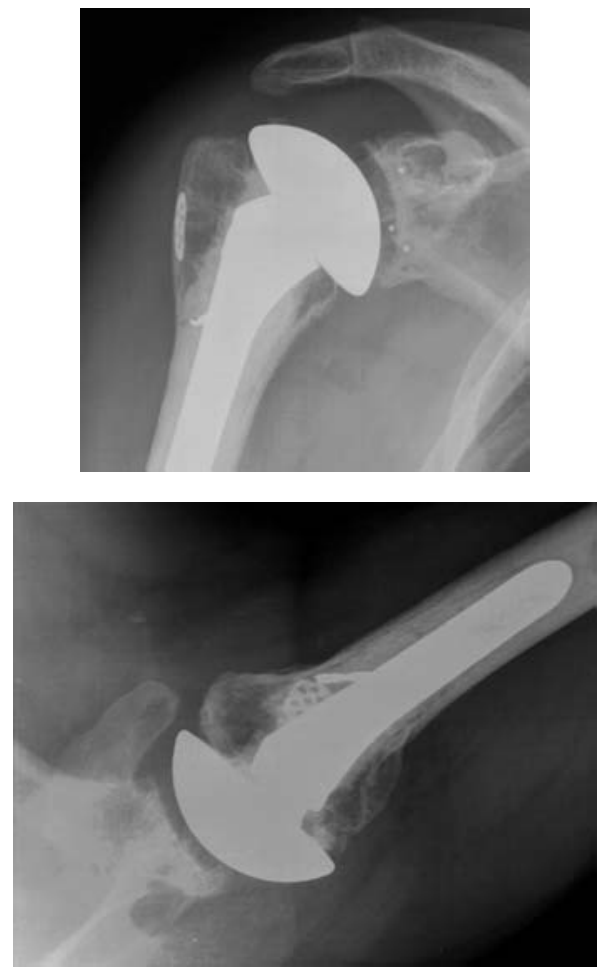

Fig. 7

Radiographs after total shoulder replacement.

der value was $87.1 \%$ (45 to 100 ). Twenty-four patients had no pain, seven had mild pain and one had moderate pain. The mean range of active anterior elevation was $154^{\circ}$ (85 to 170 ), of active abduction $152^{\circ}$ (mean 90 to 170 ) of active external rotation $39^{\circ}(5$ to 70$)$ and of active internal rotation $93^{\circ}$ (40 to 110$)$.

In the 22 shoulders without avascular necrosis of the cephalic segment, the mean Constant score was 83 points or $96 \%$ (61 to $100 \%)$ and the SSV was $93 \%$. In the ten with partial or total avascular necrosis, the mean Constant score was 66 points or $76 \%$ (46 to $100 \%$ ) and the mean SSV $73 \%$ (50 to $100 \%$ ). The Constant scores and SSV were significantly better in patients without avascular necrosis ( $\mathrm{p}$ $<0.0005)$.

Four patients had a mild to moderate malunion. The cephalic segment was in varus in three and in valgus in one. Malunion was associated with partial avascular necrosis in two patients. The overall functional results were good and not significantly different from those of the 28 patients without malunion with a mean Constant score of $87 \%$ and a mean SSV of $88 \%$.

No statistically significant differences in Constant score or SSV were found between the different types of fracture (two- and three-part versus four-part fractures). The presence of avascular necrosis and outcome were not influenced by age, gender, type of fracture or the type of reconstruction.

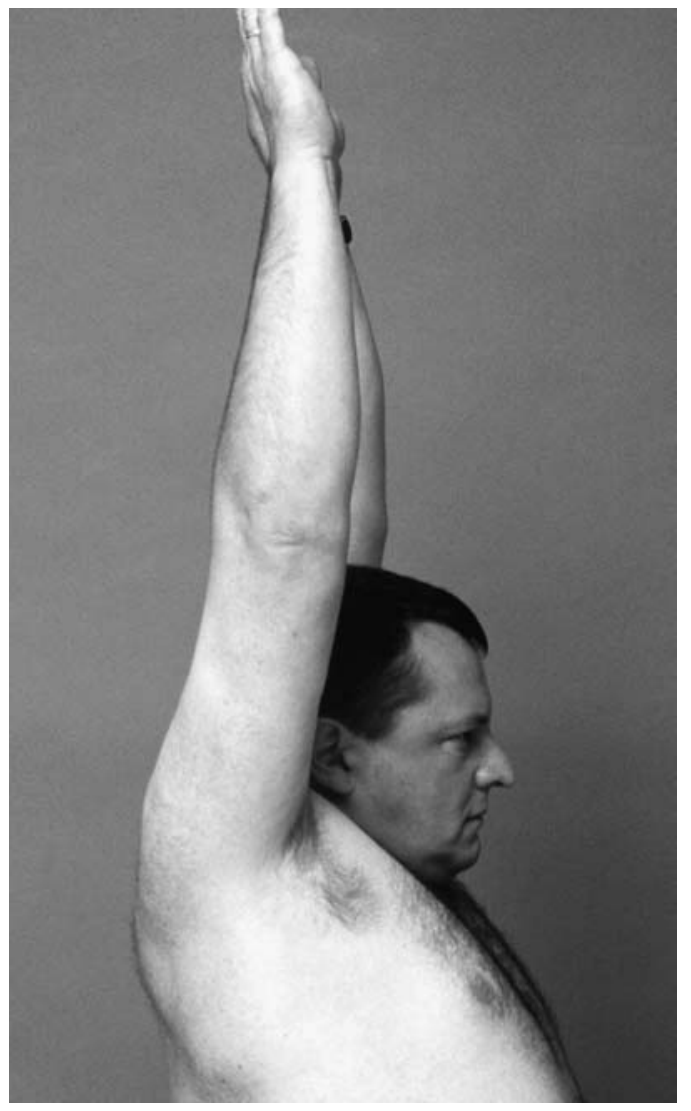

Fig. 8

Photograph showing that three years after total shoulder arthroplasty pain-free, normal shoulder function was restored.

\section{Discussion}

There is no consensus on the optimal treatment of complex fractures of the proximal humerus. ${ }^{3-5,8,10,11,13,23-26}$ In some studies the objective functional results of conservative treatment or hemiarthroplasty have been unsatisfactory. $8,12,13$ The fracture can be defined by a variety of classification systems including an assessment of bone quality and metaphyseal comminution, all of which are prone to error. None of these systems gives a clear prognosis and direction for treatment. The difficulty in accurately classifying the fracture also creates problems in reporting outcome. Overall, open reduction and internal fixation, although not in all institutions, ${ }^{4}$ have yielded satisfactory results. $6,15,16,23$ $25,27,28$ The best results are obtained if the fractures are well reduced and maintained reduced until healing has occurred. ${ }^{6,17}$ It must therefore be the goal to select fractures for open reduction and internal fixation which can be anatomically reduced. This is dependent on various factors such as the type of fracture, the quality of the bone, the technique of reduction and fixation and the experience and skill of the surgeon.

In our series, only fractures with a cortical thickness of the proximal humerus of more than $3.5 \mathrm{~mm}^{18}$ were 


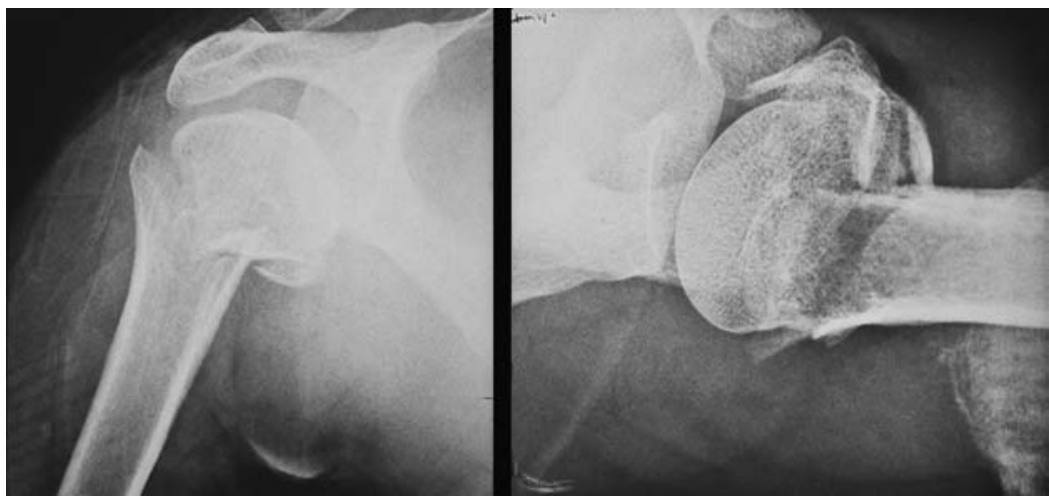

Fig. 9

Radiographs showing a valgus-impacted four-part fracture.

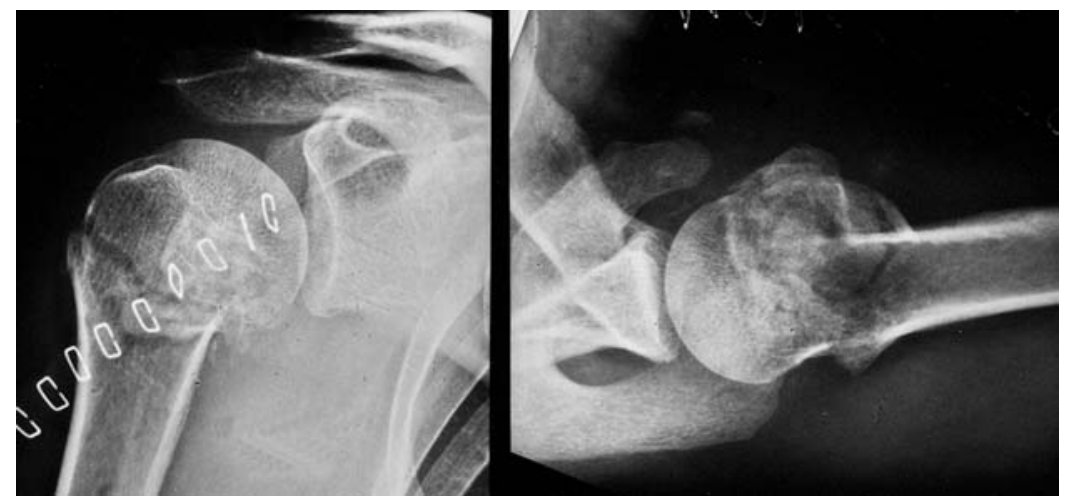

Fig. 10

Radiographs showing open reduction and internal fixation with autogenous bone graft.

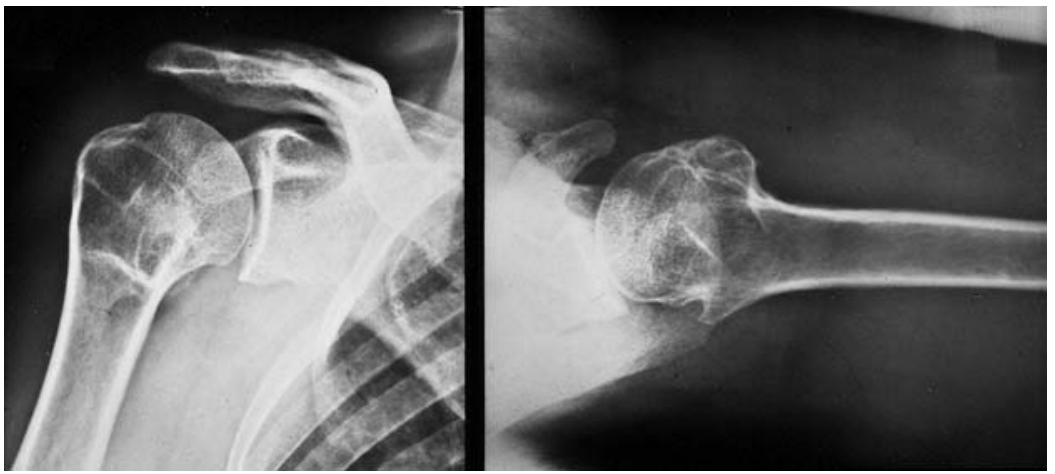

Fig. 11

Radiographs showing that eight years after operation there is no evidence of avascular necrosis.

included. The cases studied may not be representative of all the four-part fractures which a surgeon may encounter. Other authors have selected on the basis of bone quality and age, and have reported improved results. ${ }^{6,28,29}$

In our series, 33 of 35 patients were younger than 65 years and with a mean age of 45 years were young for the types of fracture considered. In addition, 20 of the 35 patients were men, who may be expected to have better overall bone quality. Most other series have reported a much greater proportion of female patients. Thus, the fractures successfully treated in our series were probably different from those treated without success in other series despite similar Neer classifications. ${ }^{4,14}$ This suggests that bone quality is an important factor in determining the outcome of open reduction and stabilisation of such fractures and should be strongly considered when selecting treatment for a fracture of the proximal humerus. However, this is not a controlled study and we do not have evidence that fractures with poorer bone quality would do less well if treated in this way. Future studies addressing specifically fractures with poor bone quality may answer this question.

Primary malreduction occurred when the use of a plate was necessary because of metaphyseal extension of the fracture, but malreduction was not associated with a particular type of fracture or a specific type of internal fixation. 
The fracture was anatomically reduced in all the 13 cases in which bone grafts were used to support the head segment (Figs 1 to 4), but four malreductions occurred in 21 cases without bone graft, this difference was not statistically significant.

The rate of avascular necrosis (Figs 5 and 6) for these fractures was high $(35 \%)$. We could not correlate the development of avascular necrosis with either the Neer type of fracture, the type of reduction, the age of the patient or other factors. Other authors have reported that the closer the medial fracture line is to the calcar, the more likely is the fracture to undergo avascular necrosis. ${ }^{30,31}$ This is believed to be because the capsular vessels are important contributors to vascularisation of the humeral head. The rate of avascular necrosis probably reflects the complexity of the fractures treated. If the head segment is deprived of its blood supply, then avascular necrosis will ensue regardless of technique of management. The rate of avascular necrosis of $35 \%$ in our study is perhaps less surprising than the lower rates reported in other studies. These lower rates may suggest that the classification systems were not applied identically. An alternative explanation is that the techniques used in our study predispose to avascular necrosis. Two cases of avascular necrosis were painful enough to warrant total joint replacement (Figs 7 and 8). At the time of review no other patient was under consideration for further surgery. The other ten cases of avascular necrosis suggest that the clinical results of anatomically reduced fractures of the proximal humerus which undergo avascular necrosis are functionally satisfactory and with a mean Constant score of 66 points or $76 \%$, this is comparable to the results of hemiarthroplasty. ${ }^{32}$

The aftercare of the patients in our series was less aggressive than that in other reports because the priority was to obtain anatomical healing rather than full early mobility. The absence of displacement of the fracture after surgery supports this approach. However, eight patients required further surgery, mostly for functional limitation. This was usually improved by removal of the implant and subdeltoid excision of adhesions.

Overall, these results confirm that the operative treatment of complex fractures of the proximal humerus gives good results, if anatomical or near anatomical reduction is obtained (Figs 9 to 11). If the bone quality, as judged by the thickness of the cortex of the proximal humeral diaphysis is good, anatomical reduction can be obtained and maintained in approximately $90 \%$ of cases. If avascular necrosis ensues, the clinical result may remain satisfactory.

No benefits in any form have been received or will be received from any commercial party related directly or indirectly to the subject of this article.

\section{References}

1. Neer CS. Shoulder reconstruction. Philadelphia: W. B. Saunders Comp, 1990:551

2. Neer CS. Displaced proximal humeral fractures: part l: classification and evaluation. J Bone Joint Surg [Am] 1970;52-A:1077-89.
3. Zyto K, Wallace WA, Frostick SP, Preston BJ. Outcome after hemiarthroplasty for three- and four-part fractures of the proximal humerus. J Shoulder Elbow Surg 1998;7:85-9.

4. Zyto K, Ahrengart L, Sperber A, Törnqvist H. Treatment of displaced proximal humeral fractures in elderly patients. J Bone Joint Surg [Br] 1997;79-B:412-8.

5. Schai P, Imhoff A, Preiss S. Comminuted humeral head fractures: a multicenter analysis. J Shoulder Elbow Surg 1995;4:319-30.

6. Resch H, Beck E, Bayley I. Reconstruction of the valgus-impacted humeral head fracture. J Shoulder Elbow Surg 1995;4:73-80

7. Kristiansen B, Kofoed $\mathbf{H}$. Transcutaneous reduction and external fixation of displaced fractures of the proximal humerus: a controlled clinical trial. J Bone Joint Surg [Br] 1988;70-B:821-4

8. Zyto K. Non-operative treatment of comminuted fractures of the proximal humerus in elderly patients. Injury 1998;29:349-52.

9. Neer CS. Displaced proximal humerus fractures: part II: treatment of three-part and four-part displacement. J Bone Joint Surg [Am] 1970;52-A:1090-103.

10. Bosch U, Skutek M, Fremery RW, Tscherne H. Outcome after primary and secondary hemiarthroplasty in elderly patients with fractures of the proximal humerus. $J$ Shoulder Elbow Surg 1998;7:479-84

11. Connor PM, D'Alessandro DF. Role of hemiarthroplasty for proximal humeral fractures. J South Orthop Assoc 1995;4:9-23.

12. Dines DM, Warren RF. Modular shoulder hemiarthroplasty for acute fractures: surgical considerations. Clin Orthop 1994;307:18-26.

13. Goldman RT, Koval KJ, Cuomo F, Gallagher MA, Zuckerman JD. Functional outcome after humeral head replacement for acute three- and four-part proximal humera fractures. J Shoulder Elbow Surg 1995;4:81-6.

14. Court-Brown CM, Garg A, McQueen MM. The translated two-part fracture of the proximal humerus: epidemiology and outcome in the older patient. J Bone Joint Surg [Br] 2001;83-B:799-804.

15. Jaberg H, Warner JJ, Jakob RP. Percutaneous stabilization for unstable fractures of the humerus. J Bone Joint Surg [Am] 1992;74-A:508-15.

16. Jakob RP, Miniaci A, Anson PS, et al. Four-part-valgus impacted fractures of the proximal humerus. J Bone Joint Surg [Br] 1991;73-B:295-8.

17. Gerber $\mathbf{C}$, Hersche $\mathbf{0}$, Berberat $\mathbf{C}$. The clinical relevance of post traumatic avascular necrosis of the humeral head. J Shoulder Elbow Surg 1998;7:586-90.

18. Tingart MJ, Apreleva M, von Stechow D, Zurakowski D, Warner JJ. The cortical thickness of the proximal humeral diaphysis predicts bone mineral density of the proximal humerus. J Bone Joint Surg [Br] 2003;85-B:611-17.

19. Siebenrock KA, Gerber $C$. The reproducibility of classification of fractures of the proximal humerus. J Bone Joint Surg [Am]1993;75-A:1751-5.

20. Sidor MI, Zuckerman JD, Lyon T, et al. The Neer classification system for proximal humeral fractures. J Bone Joint Surg [Am] 1993;75-A:1745-50.

21. Constant CR, Murley AHG. A clinical method of functional assessment of the shoulder. Clin Orthop 1987;214:160-3

22. Gerber C, Fuchs B, Hodler J. The results of repair of massive tears of the rotato cuff. J Bone Joint Surg [Am] 2000;82-A:505-15.

23. Dahners LE. Internal fixation of proximal humeral fractures. J South Orthop Assoc 1995;4:3-8

24. Esser RD. Open reduction and internal fixation of three- and four-part fractures of the proximal humerus. Clin Orthop 1994;299:244-51.

25. Cornell CN, Levine D, Pagnani MJ. Internal fixation of proximal humerus fractures using the screw-tension band technique. J Orthop Trauma 1994;8:23-7.

26. Compito CA, Self EB, Bigliani LU. Arthroplasty and acute shoulder trauma: reasons for success and failure. Clin Orthop 1994;307:27-36

27. Szyszkowitz R, Seggl W, Schleifer P, Cundy PJ. Proximal humeral fractures: management techniques and expected results. Clin Orthop 1993;292:13-25.

28. Ko JY, Yamamoto R. Surgical treatment of complex fractures of the proximal humerus. Clin Orthop 1996;327:225-37.

29. Le Bellec Y, Masmejean E, Cottias P, Alnot JY, Huten D. Internal fixation of proximal humerus fracture by "palm tree" pinning. Rev Chir Orthop Reparatrice Appar Mot 2002;88:342-8.

30. Seggl W, Weiglein A. Die arterielle Blutversorgung des Oberarmkopfes und ihre prognostische Bedeutung bei Luxationen, Frakturen und Luxationsfrakturen des Oberarmkofes. Acta Chir Austriaca 1991;23-suppl 92:1-19.

31. Brooks CH, Revell WJ, Heatley FW. Vascularity of the humeral head after proximal humeral fractures: an anatomical cadaver study. J Bone Joint Surg [Br] 1993; 75-B:132-6.

32. Hubert L, Dayez J. Results of the standard Aequalis prosthesis for proximal humeral fractures. In: Walch G, Boileau P, Molé D, eds. 2000 shoulder prostheses: two to ten year follow-up. Montpellier: Sauramps Medical, 2001:527-9. 